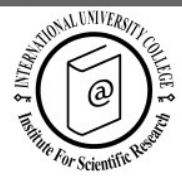

\title{
Sustainable tourism and the emergence of new environmental norms
}

\author{
Malgorzata Ogonowska ${ }^{1 *}$ and Dominique Torre ${ }^{1}$
}

Received: 15/07/2012 Accepted: 30/01/2013

\footnotetext{
${ }^{1}$ Universite de Nice-Sophia Antipolis, GREDEG, CNRS, 250 rue Albert Einstein - Bâtiment 2, 06560 Valbonne, France ; e-mails: malgorzata.ogonowska@gredeg.cnrs.fr; dominique.torre@gredeg.cnrs.fr; phones: +33 (0)4 93954393 ; +33 (0)4939543 61; fax: +33 (0)493653798

* Corresponding author
}

\begin{abstract}
Since 1990s environmental protection and awareness became major issues. Consumers are more and more aware of environmental issues and conscious of existing pollution caused by mass tourism. Consequently a new segment of demand desiring sustainable tourism products have appeared, enhancing service providers to offer this type of products. This paper analyzes the evolution of service provider's offer adapting to demand preferences modification. Using a theoretical framework, it explains how environmental quality standards become general norms in tourism industry. By analyzing cases of monopoly and duopoly, it considers different possible frameworks and strategic choices that may be implemented by the incumbent. Though, it explains the role of supply in the emergence of new environmental norms.
\end{abstract}

(C) 2013 International University College. All rights reserved

Keywords: economics of tourism, tourism products' distribution, sustainable tourism, branding policies, environmental norms.

Citation: Ogonowska, M., D. Torre (2013) Sustainable tourism and the emergence of new environmental norms. European Journal of Tourism Research 6(2), pp. 141-153

\section{Introduction}

Tourism includes a wide range of economic activities that have an important impact on the environment and on local populations of the destinations. Environmental protection and awareness became the major issues in the 1990s when the concept of sustainable development has been introduced in Our Common Future by the Brundtland Commission (World Commission on Environment and Development, 1987). Since, tourists are more and more aware of environmental issues; consequently the new segment of demand, desiring environmentally responsible products, has appeared. These new concerns modify tourist's perceptions of destinations, of accommodation brands and of intermediaries distributing tourism products (tour operators, on-line and off-line tourism agencies etc.). The tourism service providers have to adapt their offer to these changing preferences. A new concept of sustainable 
tourism has been developed and became an important issue in tourism related literature. According to Associazione Italiana Turismo Responsabile (quoted by Cracolici, Cuffaro, Nijkamp), sustainable tourism is defined as "every tourism activity that preserves for a long time the local natural, cultural and social resources, contributing to the well-being of individuals living in those tourist areas".

Meanwhile, two segments of demand co-exist: consumers, who are aware of environmental protection issues and search for sustainable tourism products, and those, who are more interested in other characteristics of the offered services (e.g. prices, luxury standards etc.). This paper analyzes the evolution of service provider's offer adapting to demand preferences modification. Using a theoretical framework, it explains how environmental quality standards become general norms in tourism industry. By analyzing cases of monopoly and duopoly, it considers different possible frameworks and strategic choices that may be implemented by the incumbent. Though, it explains the role of supply in the emergence of new environmental norms. In order to consider those questions, this paper is organized as follows. Section 2 presents the contributions of the literature on sustainable tourism and on tourism products' pricing and distribution strategies. This literature review indicates the positioning of this paper - on the crossing of those two specific issues. Then, in section 3, the model and its main results, including branding and marketing implications,

are presented. In section 4 quality enhancement question is considered. Finally, in section 5, the point is made on potential competitors' entry on the market and thus, on industry role in environmental norms' diffusion, before concluding in section 6 .

\section{Literature review}

Literature related to sustainable tourism questions is quite various and thus, is interested in diverse economic aspects of those issues. In consequence it can be classified in several categories. First identified category is found on Bramwell's and Lane's definition of sustainable tourism, 1993, that is "an economic development model conceived to improve the quality of life for the local community, and to facilitate for the visitor a high-quality experience of the environment, which both the host community as the visitors depends". In this point of view sustainable tourism ought to, first of all, guarantee the relationship between the local community and the tourists; in consequence the local governments and administrations should develop appropriate policies (for more information on this issue see Accinelli, Brida and Carrera, 2008; Caserta and Russo, 2002). Those policies should also focus on environment protection by enhancing market actors to implement ecologically responsible measures and amenities. This point was emphasized by Rivera, 2002; Shen and Zheng, 2010 and Weaver, 2005. In order to smooth the progress of the environmental policies implementation, there is a need to educate market actors (hotel management, tourism agents, tour operators, administration), as well as, the whole population with the objective to adapt people's perceptions into this new long term vision (Nita and Agheorghiesei, 2010). The implementation and adjustment of amenities and equipments more respective of environment can be impelled by demand's desires, which compose the second identified category of the literature. The environmentally aware tourist's segment may influence the service providers to invest in their facilities modernization to make them more ecological (Accinelli, Brida, Carrera and Pereyra, 2007; Brau, 2008; Claude and Zaccour, 2009; Minciu, Popescu, Padurean, Hornoiu and Baltaretu, 2010). In order to get the return on its investment, service provider may increase the prices of products including environmentally responsible amenities in comparison to traditional (more "polluting") products. Finally, price discrimination practices are also observed in natural reserves tickets pricing. Indeed local visitors (verified in the third world countries) pay lower fees then the other tourists (for more extensive analysis on this issue see Becker, 2009; Walpole, Goodwin and Kari, 2001).

None of existing papers of sustainable tourism literature is up till now concerned by the questions of pricing of environmentally responsible products (besides the issue of natural reserves tickets pricing), neither by the strategies of their distribution. To fill this gap, this paper combines the contributions of the 
articles on sustainable tourism with those developed in the literature on tourism products distribution and pricing strategies (Clemons, Hann and Hitt, 2002; Gallego and van Ryzin, 1994; Fay, 2008; Fay, 2008; Feng and Xiao, 2000; Fleishmann, Hall and Pyke, 2004a, b; Shapiro and Shi, 2008; Stokey, 1979; Zhao and Zheng, 2000). The following sections use theoretical setting to analyse, how the supply of tourism services contributes to new environmental norms' definition.

\section{The emergence of environmental norms}

This paper describes the evolution of a service provider's (hotelier or other accommodation provider) offer adapting its range of tourism products to consumers' preferences modification. These preferences are particularly influenced by progressive awareness of a number of consumers of environmental risks generated by tourism. At a certain point this sub-population becomes sufficiently large and active and then, a demand-pull movement impulses changes in tourism products' supply. Indeed, traditional brands diversify their offer, by developing new, but rather low quality, sustainable tourism products.

\section{The benchmark case}

At the initial stage, there is no information on pollution driven by mass tourism. This situation may be assimilated to the beginning of 1980's, before the Chernobyl disaster, when environmental protection and the ecology were not relevant issues. As there was no public information on eventual environmental damages, those issues have not been taken into consideration by any agent while taking any decision that could have an impact on the environment. In this case, tourists were not concerned with environmental issues and were interested in acquiring traditional/standard tourism products. The tourism service provider offered only this category of products, because there was no demand for any other type of products.

Accordingly, if $n$ potential tourists have the same propensity to pay related to the level of parameter $\alpha ; \alpha>0$ in their utility function measures in monetary terms the satisfaction that they draw from the consumption of traditional tourism product. All potential tourists purchase, or not, the standard tourism product, according to its price. If $p_{t}$ figures the price of this product, the net utility of potential tourists is given by equation (1):

$$
u_{T}=\alpha-p_{T}+\beta
$$

where $\beta$ measures the quality of the product.

Potential tourists choose to purchase the standard product if $u_{T} \geq 0$ and to reserve in the opposite case.

The service provider, which produces without costs in a situation of monopoly, determines the price maximizing its profit. This price extracts the total consumers' surplus and is given by $p_{T}=\alpha+\beta$. Then, profit depends only on the number of potential tourists (or on quantity of products potentially sold), and is given by $\pi_{T}^{*}=n(\alpha+\beta)$. Finally, all potential tourists purchase traditional standard product and pay their reservation price.

The rise of environmental issues

This second stage captures the service provider's and potential tourists' decisions related to the rise of environmental issues. Information on pollution caused by standard tourism products is made publicly available and progressively generates a movement of distrust towards traditional products and splits consumers in two subpopulations. New segment of environmentally conscious tourists $m_{0}\left(0<m_{0}<n\right)$ appears; for instance this segment is rather small. The utility that those consumers draw from the consumption of traditional products decreases, as these products are now perceived as generating pollution, and is now given by (2):

$$
u_{T}^{G}=\alpha^{\prime}-p_{T}+\beta
$$

with $\alpha^{\prime}<\alpha$. For the remaining $\left(n-m_{0}\right)$ potential tourists, utility of consuming a traditional product is still given by (1).

Since the service provider cannot apply first degree price discrimination, it has to choose 
between charging the previous price $p_{T_{1}}=p_{T}^{*}=\alpha+\beta$, but then only $\left(n-m_{0}\right)$ tourists purchase the product and the profit is $\pi_{T_{1}}=\left(n-m_{0}\right)(\alpha+\beta)$ or a lower price $p_{T_{2}}=\alpha^{\prime}+\beta$, when the profit is $\pi_{T_{2}}=n\left(\alpha^{\prime}+\beta\right)$. In both cases, the new profit is smaller than $\pi_{T}^{*}=n(\alpha+\beta)$.

Then, as the environmentally conscious population spreads the information on the pollution in its circles, there are more and more consumers aware of environmental damages. The environmentally conscious population grows and desires more environmentally respective products. At this stage, the service provider can adapt its offer to those changing preferences and start to offer also a sustainable tourism product, generating only few or no environmental damages. In order to avoid additional investments, it develops a low quality sustainable tourism product (labelled $g_{1}$ ), which provides $m_{0}$ environmentally conscious consumers with the utility given by (3):

$$
u_{g_{1}}^{G}=\alpha^{\prime \prime}-p_{g_{1}}+\gamma
$$

where the parameter $\alpha^{\prime \prime} \geq \alpha^{\prime}$ represents the environmentally conscious tourists' propensity to pay for the sustainable product, while $\gamma$ figures the quality index of the new variety, with $\gamma<\beta$. If the introduction of this new variety incurs no additional cost for the service provider, it is advantageous as soon as it allows selling the new variety of product to the environmentally conscious population at a higher price than the former one. The introduction of the new variety is then profitable for the supplier, if $\gamma \geq\left(\alpha^{\prime}-\alpha^{\prime \prime}+\beta\right)$.

Because there is still a population of tourists interested in traditional standard products, who are not concerned by environmental issues, the service provider diversifies its offer by providing two types of products to the two different populations. Thus, the service provider continues to charge the reservation price $p_{T}^{*}$ for the standard product, which is purchased by the $\left(n-m_{0}\right)$ "traditional" tourists, and charges the price $p_{g_{1}}^{*}=\alpha^{\prime \prime}+\gamma$ for the sustainable product, which is consumed by environmentally conscious population. Now, service provider's profit is $\pi_{T / g_{1}}^{*}=m_{0}\left(\alpha^{\prime \prime}+\gamma\right)+\left(n-m_{0}\right)(\alpha+\beta)$ and can be smaller or larger than the initial profit $\pi_{T}^{*}$ according to the respective values of $\alpha^{\prime \prime}, \alpha, \beta$ and $\gamma$. Whatever the values of parameters $\alpha^{\prime \prime}, \alpha^{\prime}, \alpha, \beta$ and $\gamma$ are, $\pi_{T / g_{1}}^{*}$ is larger than service provider's profit when it provides all the consumers with traditional product only $\left(\pi_{T_{1}}\right.$ or $\left.\pi_{T_{2}}\right)$.

The dynamics of environmental conscious tourists population

The population's sensibility to environmental issues depends on exogenous and endogenous factors. Scientific information on nature and causes of environmental damages represents an exogenous origin of emergence and/or growth of the environmentally conscious population. Awareness of environmental issues changes also rapidly in all countries around the world, according to diverse circumstances such as natural disasters, national and international information campaigns, education, political interventions... These events can be assimilated to exogenous shocks defining initial conditions of dynamics or modifying unexpectedly its path. After a given shock generated by one of these events, stylized facts show that two dynamics are possible. When the shock is too small or "negative", population, concerned by environmental issues, rapidly decreases to zero. Such situation has been observed, for instance, in some European countries, few years after the Chernobyl disaster or several years after the first communications on greenhouse effects during the 1990s. If the initial shock's amplitude is sufficient, the "ecological messages/values" are more or less rapidly spread among the population ${ }^{1}$. The number of environmentally conscious tourists then varies from one period to another.

This variation depends mainly and positively on two factors: 
1. The strength of the informational signal spread among "traditional" tourists' population, which makes them progressively more sensible to environmental issues. This effect is captured by following expression: $-\frac{b}{i}\left[a\left(n-m_{t-1}\right)-1\right]$, where $i>0$ stands for the quality/intensity of exogenous information while $a$ and $b$ are parameters, with $0<a$ and $0<b<<1$.

2. The environmental damages generated by standard tourism, which amplify ecological sensibility of environmentally conscious tourists. This effect is captured by following expression: $a m_{t-1}\left(n-m_{t-1}\right)$.

The resulting dynamics is provided by following expression (4):

$$
m_{t}=\max \left(n, \min \left[0, a\left(m_{t-1}-\frac{b}{i}\right)\left(n-m_{t-1}\right)+\frac{b}{i}\right]\right)
$$

It can be easily verified, that the population of environmentally conscious tourists has then three stationary equilibriums, corresponding respectively to $m^{*}=0, \quad m^{\mp}=\frac{b}{i} \quad$ and $m^{* *}=n-\frac{1}{a} \quad$ (for extensive explanation see appendix 1). Only $m^{*}$ and $m^{* *}$ are stable under adaptive expectations, while the second stationary solution $m^{\mp}$ is unstable under the same expectations. Furthermore, the following interesting result can be observed:

\section{Proposition 1}

(i) All things being equal, all increase in information on environmental damages raises the probability of convergence towards stationary equilibrium with large proportion of environmentally conscious tourists and low level of environmental damages/pollution generated by tourism.

(ii) All things being equal, a sufficiently large environmental shock tends to generate dynamics of convergence towards stationary equilibrium with large number of environmentally conscious tourists and only few environmental damages generated by tourism. Too small environmental shocks have only temporary effects and are not able to generate expansion of environmentally conscious tourists' population.

\section{Proof: see Appendix 1.}

Sustainable brand and new forms of marketing When pollution persists, environmentally conscious consumers become more sensible to ecological issues and less tolerant to polluting companies. At this point they require sustainable tourism' service providers to be truly sustainable and thus, they refuse to buy anything from a service provider which distributes also polluting products. Formally speaking, the equation (3) stops to represent the environmentally conscious tourists' utility provided by consumption of sustainable products. In this expression, $\alpha^{\prime \prime}$ progressively falls to 0 : environmentally conscious tourists then choose reservation strategy, or, in other words, boycott all of the service provider's products. When $m_{t}$ is quite important, this boycott decreases drastically the profit. Service provider, then, can react by offering the same sustainable tourism product, but under another brand name, while still distributing traditional product under the same previous brand name. This double branding strategy includes additional cost $c$, corresponding to creation of the new "environmentally responsible" brand, maintaining its quality and confidentiality of its parent company, in order to preserve its reputation. In this particular setting the environmentally conscious tourists' utility of consumption of the sustainable tourism product returns to the previous level:

$$
u_{g_{2}}^{G}=u_{g_{1}}^{G}=\alpha^{\prime \prime}-p_{g_{1}}+\gamma
$$

However, the environmentally conscious tourists' population has grown up to $m_{1}$. Each sub-population pays the corresponding reservation price, the service provider's profit is now

$$
\pi_{T / g_{2}}^{*}=m_{1}\left(\alpha^{\prime \prime}+\gamma\right)+\left(n-m_{1}\right)(\alpha+\beta)-c
$$


and it could still be smaller than $\pi_{T / g_{1}}^{*}$ if $\alpha$ "remains close to $\alpha$.

As the proportion of environmentally conscious tourists varies over time, it is not easy for the service provider to choose a long run policy. Indeed, the dynamics of $m_{t}$, described by the equation (4), is not always regular and can at some stages move towards $m^{* *}$, high equilibrium, in an oscillatory way. The quality of available information, spread by researchers, can also change and accelerate this convergence. New environmental shocks can also occur, changing sometimes the convergence path followed by tourists' population. Finally, environmentally conscious tourists, now informed of financial connections between the new "sustainable" brand and the traditional brand, distributing standard products, boycott sustainable products offered by the new brand. Subsequently, the service provider needs more definite policy.

\section{Only sustainable strategy - Investing in quality}

After the failure of the new "sustainable" brand, the service provider has to change its distribution policy. It can no longer provide both segments of the demand with the two types of products, because of the nature of environmentally conscious tourists' population. If it continues to offer both types of products, sustainable and the traditional one, it would effectively provide only the tourists not interested in environmental issues, but more in prices or luxury standards, with the traditional product, and lose the subpopulation of environmentally conscious clients. In order to maintain its market share, the service provider has to offer sustainable tourism product only. In this case, its bad reputation disappears for the environmentally conscious tourists, who then draw from sustainable products the utility given by (3) and the service provider saves the cost $c$ (as there is no more product differentiation necessary). Traditional product disappears from service provider's offer and environmental norms progressively are imposed to the whole potential tourists' population.
At this point, the service provider has two possible technological and commercial options. It can either offer the standard low quality sustainable product, i.e. the one that it was offering until now, and take the risk of dissatisfaction of traditional tourists, or enhance the quality of the sustainable product. This second option has one important consequence - it attracts tourists initially not interested in sustainable tourism products, as the sustainable tourism products, considered until now, were low quality products, in which traditional tourists were not interested.

First, if the service provider chooses to offer the low quality sustainable product, the utility function of environmentally conscious tourists is given by (3) and the utility of traditional tourists is given by (6):

$$
u_{g_{2}}^{T}=\alpha-p_{g_{2}}+\gamma
$$

As the service provider cannot price discriminate its clients, it will set the price $p_{g_{2}}^{*}=\alpha+\gamma$, acceptable to all potential tourists. The profit is then $\pi_{T / g_{3}}^{*}=n(\alpha+\gamma)$, smaller than $\pi_{T}^{*}$, but probably greater than $\left(n-m_{1}\right)(\alpha+\beta)-c$, which the service provider would get, if only traditional tourists were served in the case of boycott.

Second, if the service provider chooses to enhance the quality of the sustainable tourism product, this improvement involves specific and costly investments. For example, the hotel should be heated with renewable energy, gather rain water, engage in environment protection policies.... All these improvements incur additional cost $c^{\prime}$, with $c<<c^{\prime}$, which is amortised as usual. The advantage of this solution is that the whole population is provided with the same high quality product. If this quality is appreciated at the level $\gamma^{\prime}$ by all tourists, the utility of tourists' population not interested in environmental issues is now given by (7) and the utility of environmentally conscious tourists is expressed by (8): 


$$
\begin{aligned}
& u_{g_{4}}^{T}=\alpha-p_{g_{4}}+\gamma^{\prime} \\
& u_{g_{4}}^{G}=\alpha^{\prime \prime}-p_{g_{4}}+\gamma^{\prime}
\end{aligned}
$$

The service provider then charges the reservation price of "traditional" tourists and the profit becomes $\pi_{T / g_{4}}^{*}=n\left(\alpha+\gamma^{\prime}\right)-c^{\prime}$, which has to be compared with $\pi_{T / g_{3}}^{*}$ in order to decide, if the investment in quality is the good solution. The comparison provides following condition (9):

$$
\gamma^{\prime} \geq \gamma+\frac{c^{\prime}}{n}
$$

It is amazing to observe that the radical decrease in the environmental damages generated by tourism appears as a consequence of a modification in supply, driven by modification a group of consumers' preferences: even traditional tourists indifferent to ecological values - then purchase sustainable products.

At this moment, while taking its decision, the service provider has to take into account another eventuality. Indeed, by abandoning the traditional market, there is a possibility of a potential competitor's entry. This new competitor would focus its offer on the traditional market, on "traditional" tourists. As they are not interested in environmental issues, new competitor can provide them with a nonsustainable (polluting) product, which suits better their preferences. In such case, there is the risk for the service provider of losing a part of its market share, a proportion of its clients. This threat is strengthened, if it decides to implement the second strategy - to enhance the quality of the sustainable product, which implies a price increase. Otherwise, if the service provider decides not to improve the quality of the sustainable product, the price of this product is extremely low and makes any possible entry on the market unprofitable.

As it was underlined previously, if the service provider decides to enhance the quality of the product, it does it in order to modernise it and to make it perfectly correspond to the majority of potential tourists' preferences. When it decides to enhance the quality, it is conscious that new competitor's entry is highly likely.

New competitors and the industry role in environmental norms' diffusion

Reputation and new competitors' entry

When environmental norms make the product homogeneous, after the sustainable product's quality improvement, price increase associated to this quality enhancement opens the possibility for a potential entrant to make a new offer on the traditional market. Given that, this entrant could limit its offer to the traditional product, its costs being smaller than incumbent's costs. In this new situation, the traditional product is offered by the entrant to tourists not interested in environmental issues. The utility of tourists interested in traditional product is now given by expression (10):

$$
u_{e}^{T}=\alpha-p_{e}+\beta
$$

where $p_{e}$ figures the price of the traditional product offered by the entrant. This price is determined by the entrant, given the possible reactions of the incumbent. The last chooses among three strategies:

1. Coexistence strategy: in this case, the incumbent accepts to specialize in sustainable product. Its price can be enhanced at the level of the environmentally conscious population's reservation price. The sustainable product's price $p_{g_{5}}$ then extracts the whole consumer's surplus of this population and the incumbent's profit is given by (11):

$$
\pi_{g_{5}}=m_{1}\left(\alpha^{\prime \prime}+\gamma^{\prime}\right)-c^{\prime}
$$

2. Elimination strategy: in this case, the incumbent finds profitable to compete in price with the entrant. It decreases its price from its initial level $p_{g_{4}}$ to attract "traditional" tourists interested in traditional product offered by the entrant. The elimination price corresponds to incumbent's price of the high quality sustainable tourism product and making the 
entrant's profit equal to zero. If $c_{e}$ figures the cost incurred by the entrant to penetrate the traditional market, this elimination price $p_{g_{6}}$ solves the equation:

$\alpha-p_{g_{6}}+\gamma^{\prime}=\alpha-p_{e}+\beta$,

where $\left(n-m_{1}\right)\left(\alpha-p_{e}+\beta\right)-c_{e}=0$,

i.e., $p_{e}=\alpha+\beta-\frac{c_{e}}{n-m_{1}}$.

Finally, $p_{g_{6}}=\gamma^{\prime}-\beta+\frac{c_{e}}{\left(n-m_{1}\right)}$.

Then, incumbent's profits when implementing the elimination strategy, is given by expression (12):

$$
\pi_{g_{6}}=n\left(\gamma^{\prime}-\beta+\frac{c_{e}}{n-m_{1}}\right)-c^{\prime}
$$

3. If the service provider decides not to enhance the quality of the sustainable tourism product at the previous stage, the price is then $p_{g_{2}}=\alpha+\gamma$ and the profit is given by (13):

$$
\pi_{g_{2}}=n(\alpha+\gamma)
$$

At this point, relationship between the incumbent and the entrant can be considered as a game in which the incumbent is the leader, as it has the possibility to choose among the three possible strategies, while the entrant can only answer either by offering traditional product at price $p_{e}=\alpha+\beta$ in case 1 , or by renouncing to offer traditional product in cases 2 and 3 . The figures illustrate some of the possible outcomes of the game, according to the values of different relevant parameters.

According to figure 1, the strategy chosen by the incumbent depends, first of all, on proportion of potential tourists interested in sustainable tourism products $m$ over the overall population of potential tourists $n$, then on the levels of costs $c^{\prime}$ and $c_{e}$ and finally, on the quality of the sustainable tourism product $\gamma$ or $\gamma^{\prime}$. Depending on levels of those parameters, each strategy might be the best choice for the incumbent. Indeed, on one hand, if the number of tourists interested in sustainable products is low compared to the whole potential tourists' population, the best solution would be the third strategy i.e. the service provider should choose to offer a low quality sustainable product and not to enhance its quality. On the other hand, if the proportion of tourists interested in sustainable tourism products is relatively high among the overall potential tourists population, the incumbent should offer a high quality sustainable product. If this number is extremely high, as well as the quality of the product it offers, and the

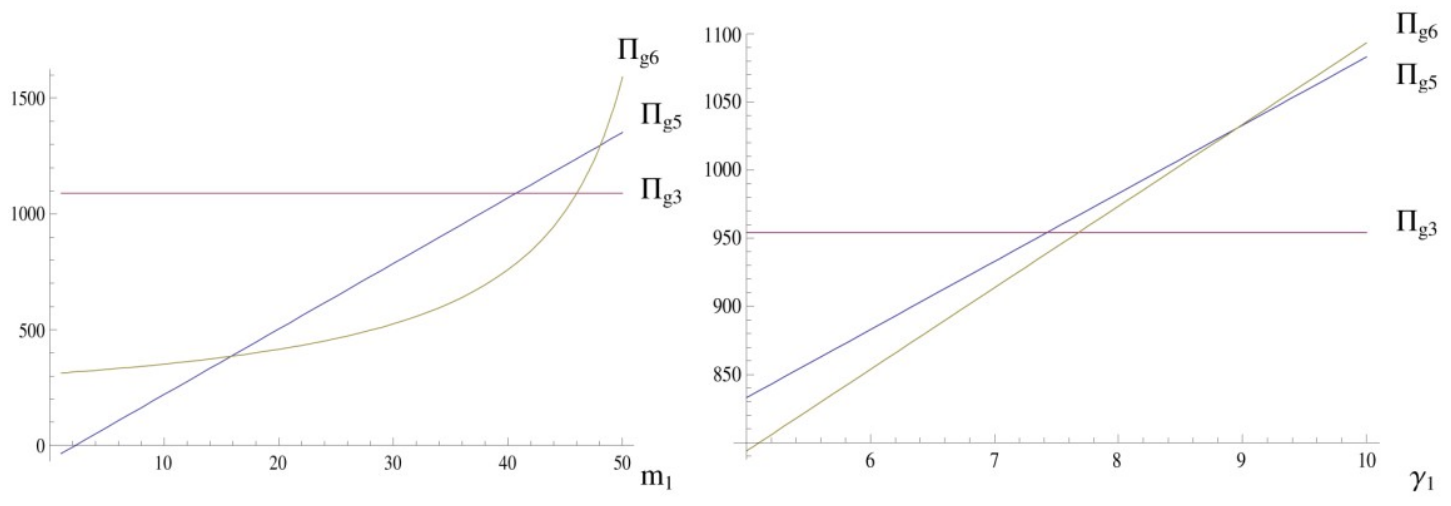

Figure 1. Comparison of incumbent's profits while implementing coexistence, elimination and no quality enhancement strategies 
traditional product's quality, offered by a potential competitor, is rather high and so are the costs it incurs, the incumbent should choose the second strategy i.e. to eliminate the entrant by practicing elimination pricing. Finally, the first strategy of coexistence with the entrant should be chosen, if the proportion of tourists interested in sustainable tourism products is relatively high compared to the overall population, but not extremely high, as well as the quality of the sustainable tourism product.

A comparison of the profits given by (11), (12) and (13) provides also the following results:

\section{Proposition 2}

All things being equal, the incumbent chooses not to enhance the sustainable product's quality, when the population of environmentally conscious tourists is low. When it increases, the coexistence strategy with a high quality sustainable product is chosen. When the population of environmentally conscious tourists is very large, the elimination strategy dominates.

\section{Proof: see Appendix 2.}

This result shows that the competitive consequences of emergence of environmental norms are not fully predictable. Some tendencies however emerge, when population of environmentally conscious tourists and the sustainable product's quality increases: the specialization of different suppliers in different segments is the more likely to appear when the population of tourists, not interested in environmental issues, is still consequent. The entrant's elimination, however, occurs when the proportion of the "traditional" tourists declines and makes entry costs too important. Still, it should be noted that as the costs of entry are essentially fixed costs, elimination should not occur, when the quality of sustainable products increases slowly and the "traditional" tourists' population decreases slowly. In this case, the fixed costs would have been already amortized when the elimination attempt is initiated by the incumbent, and given that the reservation price of the entrant is then close to zero, the elimination attempt fails.
Consolidating the environmentally conscious tourist's community

The proportion of environmentally conscious tourists depends on exogenous factors (public news, ecological shocks, extreme meteorological events...). Public scientific information also has an impact on population's interest in environmental issues and norms. The proportion of environmentally conscious tourists, then, evolves during time according to endogenous network effects. Until now, it was considered that these movements create new constraints for the tourism industry suppliers, who react passively to the norms' and mentalities' evolution. The previous section, however, shows that environmental norms' modification can generate two different consequences in competitive environment of a given service supplier. When the tourists' population is divided in two sub-populations of quite the same importance, the situation is more critical for the incumbent. The incumbent is frequently under competitor's pressure, which can take a part of its market shares. In this case, the supplier can add its own private contribution to the public information on the environmental damages caused by traditional polluting tourism products. When modifications generated by environmental norms can have a possible impact, it could spread additional information on environmental damages. This information, labelled $j$, which has to be distinguished from the scientific information $i$, can have important consequences - provide a pure exogenous signal that increases tourist's sensibility to environmental issues. Equation (4) then becomes (14):

$$
m_{t}=\max \left(n, \min \left[0, a\left(m_{t-1}-\frac{b}{i}\right)\left(n-m_{t-1}\right)+\frac{b}{i}+j\right]\right)
$$

The consequence of this additional incumbent's contribution to available information is to change the outline of network dynamics' equilibrium, without moving the populations' stationary equilibrium (see Appendix 3 for details).

\section{Concluding remarks and further research}

The paper analyzes the evolution of service provider's offer, in the situation of monopoly, adapting to demand preferences' modification. 
As consumers become progressively more and more aware of environmental damages caused by massive tourism, because of public information on pollution becoming available, a sub-population of environmentally conscious tourists, desiring sustainable tourism products, appears. Progressive growth of this subpopulation, driven by information diffusion, leads the service provider to diversify its offer by developing sustainable tourism product. As environmentally conscious tourists become extremely sensible to ecological issues and start to boycott products distributed by the service provider, which offers also traditional products, it develops a new specific brand in order to distribute sustainable tourism product. This double branding strategy, implying additional cost, in order to preserve sustainable tourism product's good reputation, enables the service provider to price discriminate its clients. However, this situation, beneficial for the service provider, may last only for the short period of time, as the supplier cannot indelibly conceal financial links existing between the two brands. In order to avoid another boycott movement, the service provider adopts an "only-sustainable" strategy - it abandons the traditional product and distributes the sustainable one only. In this situation, ecological standards become general norms. At this point, it chooses among two possible solutions: offer standard (low quality) sustainable tourism product or enhance its quality, in order to satisfy the whole population, as there are still some tourists more interested in luxury standards than in ecological issues. This quality enhancement incurs an additional cost related to specific investments. The main danger, resulting from the quality enhancement strategy, is that this situation attracts a new entrant, which can distribute standard/traditional product only, at a very advantageous price, such as "traditional" tourists (not interested in environmental issues) could choose this cheaper traditional product. At this moment, the strategy chosen by the incumbent depends on the proportion of environmentally conscious tourists among the whole tourists population, on the sustainable tourism product's quality level and on both suppliers costs' levels. Main results of this paper are the following. If the number of environmentally conscious tourists is low, the service provider/incumbent chooses not to enhance the quality of the sustainable product in order to maintain low price of this product and thus, to serve out all the consumers and maintain all its market shares. Otherwise, if the proportion of environmentally conscious tourists is relatively high, the service provider chooses a co-existence strategy with the new entrant and supplies only this subpopulation, and lets its competitor offer traditional product on the traditional market. The third strategy potential competitor's elimination - is implemented when the environmentally conscious population is extremely high and the quality of the sustainable product offered is also very high. In such situation, the incumbent may lower its price to the level making the potential entrant's profits equal to zero. This strategy is quite complicated to implement, as it requires very specific conditions. In most cases the strategy of co-existence dominates.

Possible extension of the model is to study the impact of local population on the service provider's strategic choices and on environmental norms' adoption.

\section{Acknowledgments}

Authors gratefully acknowledge Claudio Piga and Ulrike Gretzel for their comments on preliminary versions of the paper, which were presented at ENTER 2011 Conference in Innsbruck, Austria, and at the Workshop on The Economics and Management of Leisure, Travel and Tourism in Rimini, Italy. We thank all the participants of $3^{\text {rd }}$ QATEM Workshop in Corte, France, for their precious comments on latest version of the paper.

\section{Endnote:}

1 Katrina hurricane or Fukushima nuclear disaster created such reactions in Europe, North-America and Japan

\section{References}

Accinelli, E., Brida, J.G., and Carrera, E. (2008). A good policy of sustainable tourism. Revista de Administración, Finanzas y Economia, 2(2), 150-161.

Accinelli, E., Brida, J.G., Carrera, E., and Pereyra, J. (2007). The effects of environmental investment of changes in tourism demand. Tourismos: An International 
Multidisciplinary Journal of Tourism 2(2), 129-140.

Becker, N. (2009). A comparative analysis of the pricing systems of nature reserves. Tourism Economics, 15(1), 193-213.

Brau, R. (2008). Demand-driven sustainable tourism? A choice modelling analysis. Tourism Economics, 14(4), 691-708.

Briassoulis, H (2002). Sustainable tourism and the question of the commons. Annals of Tourism Research, 29(4), 1065-1085.

Budeanu, A. (2005). Impacts and responsibilities for sustainable tourism: a tour operator's perspective. Journal of Cleaner Production 13, 89-97.

Caserta, S., and Russo, A. P. (2002). More means worse: asymmetric information, spatial displacement and sustainable heritage tourism. Journal of Cultural Economics, 26(4), 245-260.

Claude, D., and Zaccour, G. (2009). Investment in tourism market and reputation. Journal of Public Economic Theory, 11(5), 797-817.

Clemons, E.K., Hann, I-H., and Hitt, L.M. (2002). Price dispersion and differentiation in online travel: an empirical investigation. Management Science, 48(4), 534-549.

Cracolici, M. F., Cuffaro, M., and Nijkamp, P. (2009). Tourism sustainability and economic efficiency - a statistical analysis of Italian provinces. Working Paper. URL: ftp://zappa.ubvu.vu.nl/20090023.pdf

Fay, S. (2008). Reverse pricing: the role of customer expectations. Working Paper. University of Florida, Gainesville, FL, USA.

Fay, S. (2009). Competitive reasons for the name-your-own-price channel. Marketing Letters, 20(3), 277-293.

Feng, Y., and Xiao, B. (2000). A continuous-time yield management model with multiple prices and reversible price changes. Management Science, 46(5), 644-657.

Fleischmann, M., Hall, J.M., and Pyke, D.F. (2004a). Smart pricing. MIT Sloan Management Review Winter, 9-13

Fleischmann, M., Hall, J.M., and Pyke, D.F. (2004b) Smart pricing: linking pricing decisions with operational insights. ERIM Report Series Research in Management. reference number: ERS-2004-001-LIS, 119.

Gallego, G., and van Ryzin, G.J. (1994). Optimal dynamic pricing of inventories with stochastic demand over finite horizons. Management Science, 40(8), 999-1020.
Hotelling, H. (1929). Stability in competition. Economic Journal. 39, 40-57.

Minciu, R., Popescu, D., Padurean, M., Hornoiu, R., and Baltaretu, A. (2010). Commercialization of holidays in the protected natural areas-form of the sustainable development in tourism. Amfiteatru Economic, 12(27), 83-98.

Nita, V., and Agheorghiesei, D. T. (2010). The perception of the students specializing trade, tourism and services on the importance of the concept of sustainable development in commercial activities. Amfiteatru Economic, 12(27), 66-82.

Rivera, J. (2002). Assessing a voluntary environmental initiative in the developing world: The Costa Rican certification for sustainable tourism. Policy Sciences, 35, 333-360.

Shapiro, D., and Shi, X. (2008). Market segmentation: the role of opaque travel agencies. Journal of Economics and Management Strategy, 17(4), 803-837.

Shen, H., Zheng, L. (2010). Environmental management and sustainable development in the hotel industry: a case study from China. International Journal of Environment and Sustainable Development, 9(1/2/3), 194-206.

Stokey, N.L. (1979). Intertemporal price discrimination. Quarterly Journal of Economics, 93(3), 355-371.

Walpole, M. J., Goodwin, H. J., and Ward, K. G. R. (2001). Pricing policy for tourism in protected areas: lessons from Komodo National Park, Indonesia. Conservation Biology, 15(1), 218-227.

Weaver, D. B. (2005). Comprehensive and minimalist dimensions of ecotourism. Annals of Tourism Research, 32(2), 439455.

World Commission on Environment and Development (1987). Our Common Future. Oxford, Oxford University Press.

Zhao, W., and Zheng Y-S. (2000). Optimal dynamic pricing for perishable assets with nonhomogeneous demand. Management Science, 46(3), 375-388. 


\section{Appendix1}

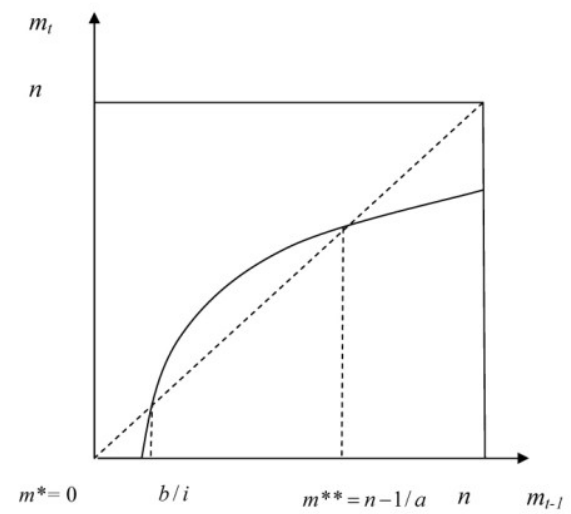

The size of the networks grows slowly

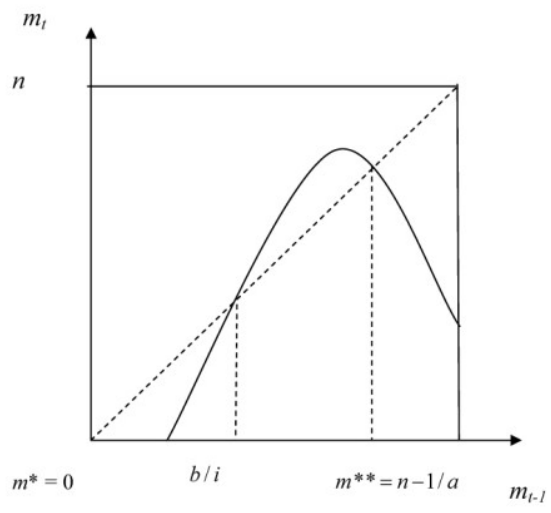

The size of the network grows rapidly and this growth is reversible

Figure 2. Dynamics of the environmentally conscious tourists' population

\section{Appendix 1: Proof of Proposition 1}

Figure 2 presents two cases of environmentally conscious tourists' population dynamics. The left-side of the figure presents slow dynamics with population' tendency to grow moderately when the proportion of environmentally conscious tourists is small and the damages are important, while it decreases also moderately when the population of environmentally conscious tourists is large and the level of damages - small. The equilibriums $m^{*}$ and $m^{* *}$ are then stable. The right-side corresponds to rapid dynamics of environmentally conscious population. In this case also the two equilibriums $m^{*}$ and $m^{* *}$ are stable. The difference between these two cases is that, outside equilibrium the convergence towards the low or the high equilibrium is monotonic in the first case and can be oscillatory in the second case, for large initial environmental shocks essentially.

Small positive shocks in case of small proportion of environmentally conscious tourists generate a short term increase of this population, with a tendency to decrease to $m^{*}$. When the initial shock or one of the subsequent positive shocks is sufficient to bypass $m^{\mp}$, the dynamics joins more or less rapidly the second stable equilibrium $m^{* *}$.

\section{Appendix 2: Proof of Proposition 2}

A comparison of expressions (11) and (13) shows that the coexistence strategy is possible when $m_{1}\left(\alpha^{\prime \prime}+\gamma^{\prime}\right)-n(\alpha+\gamma) \geq c^{\prime}$, which, given that $\gamma^{\prime}>\gamma$, becomes more probable when $m_{1}$ increases. The profit of elimination strategy, given by (12), tends to infinity when $m_{1}$ is close to $n$, which makes it - for such values of $m_{1}-$ greater than the other profits. From these two observations Proposition 2 is deduced. 
Appendix 3: Effect of the service provider's action on the diffusion of environmental norms

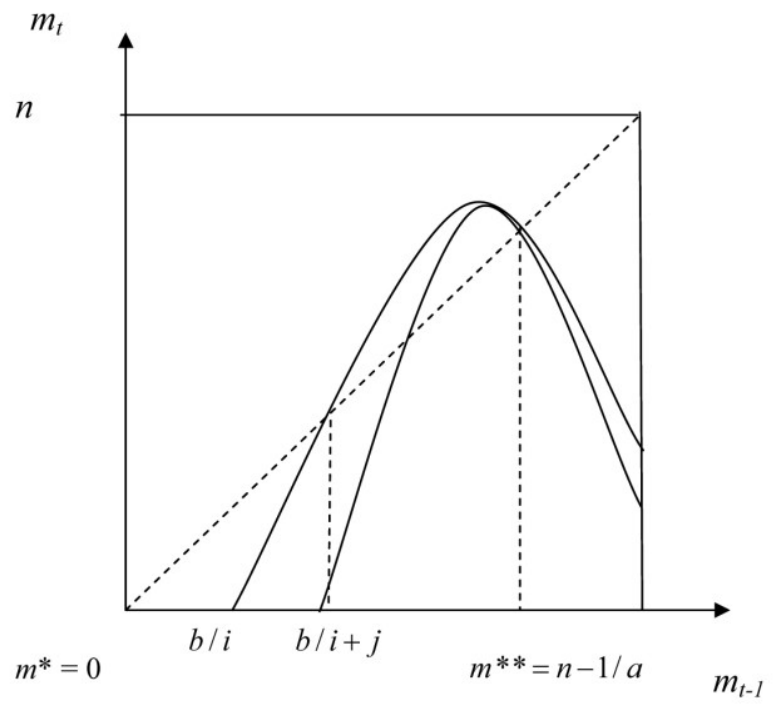

The size of the network grows rapidly and this growth is reversible

Figure 3. Effects of service provider's action on the diffusion of environmental norms 